\title{
Treponema pallidum Antibody Measurement
}

National Cancer Institute

\section{Source}

National Cancer Institute. Treponema pallidum Antibody Measurement. NCI Thesaurus.

Code C132388.

The determination of the amount of Treponema pallidum antibody in a biological sample. 